IZA DP No. 4854

Loss Aversion and Intertemporal Choice:

A Laboratory Investigation

Robert J. Oxoby

William G. Morrison

March 2010 


\title{
Loss Aversion and Intertemporal Choice: A Laboratory Investigation
}

\author{
Robert J. Oxoby \\ University of Calgary \\ and IZA \\ William G. Morrison \\ Wilfrid Laurier University \\ Discussion Paper No. 4854 \\ March 2010 \\ IZA \\ P.O. Box 7240 \\ 53072 Bonn \\ Germany \\ Phone: +49-228-3894-0 \\ Fax: +49-228-3894-180 \\ E-mail: iza@iza.org
}

Any opinions expressed here are those of the author(s) and not those of IZA. Research published in this series may include views on policy, but the institute itself takes no institutional policy positions.

The Institute for the Study of Labor (IZA) in Bonn is a local and virtual international research center and a place of communication between science, politics and business. IZA is an independent nonprofit organization supported by Deutsche Post Foundation. The center is associated with the University of Bonn and offers a stimulating research environment through its international network, workshops and conferences, data service, project support, research visits and doctoral program. IZA engages in (i) original and internationally competitive research in all fields of labor economics, (ii) development of policy concepts, and (iii) dissemination of research results and concepts to the interested public.

IZA Discussion Papers often represent preliminary work and are circulated to encourage discussion. Citation of such a paper should account for its provisional character. A revised version may be available directly from the author. 
IZA Discussion Paper No. 4854

March 2010

\section{ABSTRACT}

\section{Loss Aversion and Intertemporal Choice: A Laboratory Investigation}

We present results from a laboratory study of loss aversion in the context of intertemporal choice. We investigate whether the provision of (windfall) endowments results in different elicited discount rates relative to subjects who earn income or earn and retain the income for a period before making intertemporal decisions. We hypothesize that loss aversion in an intertemporal choice yields higher discount rates among subjects earning and retaining. Our results support this hypothesis: among subjects who earn and retain their income we elicit substantially higher discount rates relative to those experiencing a windfall gain.

JEL Classification: C91, D91

Keywords: intertemporal choice, discount rates, experiments

Corresponding author:

Robert J. Oxoby

Department of Economics

University of Calgary

2500 University Drive NW

Calgary, Alberta T2N 1N4

Canada

E-mail: oxoby@ucalgary.ca 


\section{Introduction}

In this paper, we explore the role of loss aversion in intertemporal decision making, using a laboratory experiment. We implement loss aversion using a unique design wherein (i) individuals either receive an endowment of money income or earn money income in the laboratory and (ii) where income earned in the lab may be retained by subjects for a week prior to making incentive compatible intertemporal choices. Our results show that earning income (as opposed to receiving an endowment) does not by itself create a sufficient sense of entitlement to generate significant changes in elicited discount rates. However, we do find compelling evidence that loss aversion, arising from income that is earned in the laboratory and retained prior to decision making, increases average discount rates by over $60 \%$. This result is particularly important for those interested in studying savings and other intertemporal financial decisions in the laboratory.

\section{An intertemporal choice experiment}

We elicited discount rates from participants using a method utilized in many studies of intertemporal decision making (e.g., Coller and Williams, 1999; Harrison et al., 2002; McLeish and Oxoby, 2007). This elicitation procedure involved participants completing Table 1 by indicating whether they preferred option A (a constant amount of money to be received after the laboratory session) or option B (a larger amount of money to be received two weeks after the session) across eleven different alternatives. The same table was used in each of the treatments described below.

Table 1 about here

In Table 1, the amounts under 'option B' represent two-week discount rates ranging from $0 \%$ to $27.5 \%$. The point in the table where an individual ceases choosing option $\mathrm{A}$ and begins choosing option B (i.e., their cross-over point) proxies the individuals two- 
week discount rate (outcome variable: $A$-rate). Individuals were compensated for their participation based on the answers they provided in Table 1: at the end of the experiment, one of the twelve payoff alternatives was randomly selected and each individual received a (potentially post-dated) check for the dollar amount corresponding to their choice. ${ }^{1}$ This procedure was followed across all the treatments described below. In addition to this payment for participation, individuals were also paid a $\$ 5$ cash showup fee for attending the session. ${ }^{2}$

It is worth commenting on three aspects of our design. First, in Table 1 under payoff alternative 1 option B returns 0\% (i.e., the individual decides between $\$ 40$ today and $\$ 40$ in two weeks). This was done as a means to check individuals' understanding of the problem: if individuals value receiving money sooner rather than later, all individuals should prefer option A when both options return $\$ 40$. Secondly, in order to compensate individuals for any transaction costs (real or imagined) regarding the money, we chose significantly large discount rates (i.e., larger than those paid by financial institutions). We do not feel that this compromises our results as our primary interest is in the effect of our treatments on the elicited discount rates not the value of the interest rates per se. ${ }^{3}$

Lastly, we did not use a front-end delay (e.g., option A amounts in Table 1 involve money being available immediately; cf. Coller and Williams, 1999, and McLeish and Oxoby, 2007). Harrison et al. (2005) argues that a front-end delay is necessary to eliminate (or reduce) the immediacy of potential consumption and the perceived differences in transaction costs between the two options. As mention above, we have

\footnotetext{
${ }^{1}$ For example, suppose after an individual completed Table 1, question 6 was randomly chosen to determine her payment for participation. If in her response to this question she indicated that she preferred $\$ 40$ to be paid immediately, she received a check dated the day of the experiment for $\$ 40$. If her response to this question indicated she preferred $\$ 45$ in two weeks, she received a check on the day of the session for $\$ 45$ but post-dated for two weeks from the date of that session. Full instructions for the experiment are available from the authors upon request.

2 The show-up fee was used as an inducement to encourage individuals to attend the experiment. We chose to pay all individuals by check regardless of the implemented option to maintain consistency between those receiving a check dated currently and those receiving a post-dated check. In reviewing the checks used in the experiment, we found that no post-dated checks were cashed before the date indicated on the check.

${ }^{3}$ Previous studies (Coller and Williams, 1999; Harrison et al., 2002) have utilized interest rates which more closely mirror those paid by banks. However, these studies also used longer time horizons (e.g., choices between amounts to be received in three or six months).
} 
controlled for perceived transaction cost differences by paying according to discount rates that are significantly higher than market rates and by paying individuals by check. With respect to the immediacy of consumption, since our objective was to evoke loss aversion we specifically avoided using a front-end delay in order to exploit this immediacy and to create an effect related to immediate versus deferred consumption.

\subsection{Treatments}

We conducted three treatments. In our endowment treatment individuals were simply asked to complete Table 1 knowing that their payment would be based on their answer to a randomly selected payoff alternative. As such, participants were implicitly endowed with $\$ 40$ over which they made intertemporal choices. At the end of the session, participants received a $\$ 5$ cash show-up fee and a check payable the day of the session for $\$ 40$ or post-dated for a larger amount.

In our earnings treatment, participants were given a twenty-question quiz consisting of questions from the Graduate Record Exam (GRE). Participants were told they could earn either $\$ 20$ or $\$ 40$ based on their exam performance. If they answered at least ten questions correctly they would earn $\$ 40$; if their score on the exam was less than ten questions correctly answered they would receive $\$ 20.4$ This earned money was subsequently used when individuals completed Table 1 . The central motivation in this treatment was to see (i) if earning the money (receivable after the session) would create a sense of entitlement or legitimacy of these assets as has been identified in experiments on social preferences (Cherry et al., 2002; Oxoby and Spraggon, 2008) and (ii) if this sense of entitlement or asset legitimacy affected elicited discount rates. Our hypothesis was that individuals would feel they had earned the $\$ 40$ being used as the default option in Table 1. As in the endowment treatment, individuals received a $\$ 5$ cash show-up fee and a check dated for a chosen amount based on a randomly selected amount from their responses to the payoff alternatives in Table 1.

\footnotetext{
${ }^{4}$ This threshold was chosen based on previous experiments in order to ensure that most participants would earn $\$ 40$ while still requiring that they exert significant effort. All participants did sufficiently well on the selected questions to reach the $\$ 40$ threshold.
} 
In our returning treatment, individuals participated in two sessions. In session 1 they earned money as in the earnings treatment but were paid these amounts in cash at the end of the session. Participants were then told they had an opportunity to receive additional funds in session the following week in which they were required to bring the amount they had earned in current session. In this subsequent session, participants were asked to put the money they had previously earned into envelopes that were collected by the experimenter. Participants then completed Table 1 and received a $\$ 5$ show-up fee and a check based on a randomly selected alternative from Table 1. Our hypothesis in this session was that both the earning behaviour and the fact that individuals had the money in their possession for a week would create a stronger sense of entitlement and affect their intertemporal decisions. In this treatment, individuals only received a $\$ 5$ show-up fee for participation in the final session.

In addition to the data we collected regarding participants' intertemporal preferences using Table 1, we also asked participants to complete a short questionnaire at the end of each session. In addition to questions regarding demographic information, the questionnaire also included two questions regarding individuals attitudes towards the money used in the experiment:

1. Outcome variable: asset legitimacy 1, AS1: 'I am entitled to the money I received for participating in the experiment'. (Answered using a 1 to 7 scale representing 'strongly disagree' to 'strongly agree'.)

2. Outcome variable: asset legitimacy 2, AS2: 'I earned the money I am receiving for participating in the experiment'. (Answered using a 1 to 7 scale representing 'strongly disagree' to 'strongly agree'.)

Participants in the returning treatment were also asked the following yes/no questions:

1. Is the cash you brought to today's experiment the same bills you were given in the previous session?

2. If not, did you spend the cash you were given in the previous session? 


\subsection{Hypotheses}

Our hypotheses for this experiment revolve around the idea of loss aversion (e.g., Kahneman et al., 1991). We hypothesize that if individuals are resistant to putting off current consumption (i.e., treating a potential reduction in current consumption as a "loss") they should require greater compensation for deferring consumption. This greater compensation would manifest itself in Table 1 via individuals choosing higher crossing points (i.e., choosing option A for higher payoff alternatives effectively requiring a higher interest rate to put off current consumption).

\section{Hypothesis 1}

Participants will experience a greater sense of loss aversion in the Earnings and Returning treatments relative to the Endowment treatment. This should be manifest in higher values of Arate (i.e., higher cross-over points) for participants in the Earnings and Returning treatments relative to the Endowment treatment.

We further hypothesize that increasing the sense of asset legitimacy regarding money used in the experiment should increase an individual's sense of entitlement and therefore increase the presence of loss aversion with respect to deferring current consumption.

\section{Hypothesis 2}

Participants' responses AS1 and AS2 will be higher in (i) the Earnings treatment relative to the Endowment treatment, (ii) the Returning treatment relative to the Endowment treatment, and (iii) the Returning treatment relative to the Earnings treatment.

\section{Results}

A total of 75 individuals participated in the study, with 24 and 26 individuals participating in the 'endowment' and 'earnings treatments'. A total of 34 individuals participated in the first session of the returning treatment with 26 individuals 
participating in the second session in which discount rates were elicited. ${ }^{5}$ The experiments were conducted using the software developed by Fischbacher (2007). In terms of demographic information regarding participants, participants were evenly split across gender (58\% male) and ages ranged between 19 and $23 .{ }^{6}$

Table 2 provides the summary statistics from the sessions across treatments. In terms of our primary variable of interest (the variable $A$-rate), we find no statistically significant differences in participants' responses between the endowment and earnings treatments (Wilcoxon $p=0.623$ ). However, non-parametric Wilcoxon tests reject the hypotheses that $A$-rate responses in the returning treatment are drawn from the same distribution as those in the endowment and earnings treatments $(p<0.01$ in each comparison). Thus, we find that individuals in the returning treatment demonstrated, on average, discount rates that were over $60 \%$ higher than participants in our other treatments. We take this as partial support for Hypothesis 1.

Table 2 about here

With respect to Hypothesis 2, we find no differences in participants' responses regarding whether or not they were entitled to the money they received (i.e., outcome variable AS1) across all groups. However, we find that participants in the earnings and returning treatments felt they earned the money received more than those in the endowment treatment (Wilcoxon $p<0.05$ for variable AS2 from question 2). We identified no differences between the earnings and returning treatments in this regard. Thus we only find partial support for Hypothesis 2 with respect to AS2, but reject the hypothesis with respect to the variable $A S 1$.

With respect to the additional questions answered by participants in the returning treatment (i.e., questions 3 and 4), all participants indicated that the cash

${ }^{5}$ Despite some attrition in the second session of the returning treatment, we found no systematic differences between those who returned and those who did not in terms of gender, age or educational status.

${ }^{6}$ In an analysis of the data with respect to demographic information collected, we found no differences across the responses of men and women (cf. Coller and Williams, 1999; McLeish and Oxoby, 2007). 
brought to the second session was not the same as that given in the previous session and $88 \%$ of participants indicated that they had spent the money given to them in the first session. This provides some explanation for the higher discount rates elicited in this treatment. If participants had spent the money, this suggests that they considered that money truly to be theirs (as opposed to, say, money belonging to the experimenter). As such deferring use of the money by two weeks would require forgoing current consumption or incurring a loss as suggested by the research of Kahneman et al. (1991). On the other hand, participants in the endowment and earnings treatment may have viewed the money they received as a gain. Since incurring a loss is more costly than the change in well-being initiated by a similarly sized gain, participants in the returning treatment (who could experience a $\$ 40$ loss to current consumption) required greater compensation for deferring consumption relative to those in the endowment and earnings treatments (where $\$ 40$ gains were experienced). This greater compensation was manifest through higher required rates of interest to wait two weeks for payment (i.e., higher elicited discount rates).

\section{Discussion}

Our experiment demonstrates that loss aversion can be implemented in experiments involving intertemporal decisions by following a protocol whereby participants first earn money income in the laboratory and then retain this money for a period of time prior to the decision of interest.

One area of growing interest where such an approach will be important is the study of behavioural aspects of savings decisions. Existing field evidence on savings behavior suggests that individuals do not save enough for the future or for contingent events. For example, with respect to savings for retirement, empirical evidence indicates that many individuals either recognize that they should save while taking no action to increase savings, or they have a downward bias concerning how much they are saving or need to save (Loewenstein et al, 1999; O’Donoghue and Rabin, 1999, Dominitz et al, 2002). In explaining these findings, many have turned to the role of quasi-hyperbolic discounting (e.g., Loewenstein and Prelec, 1992; Laibson, 1997; O'Donoghue and Rabin, 2001). 
However, as suggested by Frederick et al (2002) other considerations may influence intertemporal decision making. One such behavior is loss aversion and our results suggest that researchers who wish to explore savings behaviour through laboratory experiments need to account for this in their experimental design. 


\section{References}

Cherry, T. L., Frykblom, P., Shogren, J. F., 2002. Hardnose the dictator. American Economic Review 92 (4), 1218-1221.

Coller, M., Williams, M. B., 1999. Eliciting individual discount rates. Experimental Economics, 2: 107-127.

Dominitz, J., Manski, C.F., and Heinz, J., 2002, Social Security Expectations and Retirement Savings Decisions, NBER Working Paper 8718.

Frederick, S., Loewenstein, G., O'Donoghue, T., 2002. Time Discounting and Time Preference: A Critical Review. Journal of Economic Literature, 40(2): 351-401.

Harrison, G. W., Lau, M. I., Rutström, E. E., Sullivan, M. B., 2005. Eliciting risk and time preferences using field experiments: Some methodological issues. In: Carpenter, J., Harrison, G., List, J. (Eds.), Field Experiments in Economics. Vol. 10 of Research in Experimental Economics. JAI Press, Greenwich, CT, pp. 337-372.

Harrison, G. W., Lau, M. I., Williams, M. B., 2002. Eliciting individual discount rates in Denmark: A field experiment. American Economic Review 92 (5): 1606-1617.

Kahneman, D., Knetsch, J. L., Thaler, R. H., 1991. The endowment effect, loss aversion, and status quo bias. Journal of Economic Perspectives 5 (1): 193-206.

Laibson, D., 1997. Golden Eggs and Hyperbolic Discounting. Quarterly Journal of Economics, 112(2): 443-77.

Loewenstein, G., D. Prelec, and R. Weber, 1999, What Me Worry? A Psychological Perspective on Economic Aspects of Retirement, in Behavioral Dimensions of Retirement Economics, H. Aaron (ed.), The Brookings Institution.

Loewenstein, G., Prelec, D., 1992. Anomalies in Intertemporal Choice: Evidence and an Interpretation. Quarterly Journal of Economics, 107(2): 573-97.

McLeish, K. N., Oxoby, R. J., 2007. Gender, affect and intertemporal consistency: An experimental approach. IZA working paper 2663.

O'Donoghue, T., and M. Rabin, 1999, Procrastination in Preparing for Retirement, in Behavioral Dimensions of Retirement Economics, H. Aaron (ed.), The Brookings Institution. 
O'Donoghue, T., Rabin, M, 2001. Choice and Procrastination. Quarterly Journal of Economics, 116(1): 121-160.

Oxoby, R. J., Spraggon, J., 2008. Yours and mine: Property rights in dictator games. Journal of Economic Behaviour and Organization 65: 703-713.

Thaler R., Bernartzi S., 2004. Save More Tomorrow: Using Behavioral Economics to Increase Employee Saving, Journal of Political Economy, 112(1):164-187.

Thaler R., Sunstein C., 2008 Nudge - Improving decisions about health, wealth and happiness. New Haven and London: Yale University Press.

Tversky, A., Kahneman, D., 1991. Loss aversion and riskless choice. Quarterly Journal of Economics. 


\begin{tabular}{|c|c|c|c|c|}
\hline $\begin{array}{c}\text { Payoff } \\
\text { Alternative }\end{array}$ & $\begin{array}{l}\text { Option A } \\
\text { (receivable } \\
\text { today) }\end{array}$ & $\begin{array}{c}\text { Option B } \\
\text { (receivable in } \\
2 \text { weeks) }\end{array}$ & \multicolumn{2}{|c|}{$\begin{array}{c}\text { Preferred } \\
\text { Option } \\
\text { (circle A or B) }\end{array}$} \\
\hline 1 & $\$ 40$ & $\$ 40$ & $\mathrm{~A}$ & B \\
\hline 2 & $\$ 40$ & $\$ 41$ & A & B \\
\hline 3 & $\$ 40$ & $\$ 42$ & A & B \\
\hline 4 & $\$ 40$ & $\$ 43$ & A & B \\
\hline 5 & $\$ 40$ & $\$ 44$ & A & B \\
\hline 6 & $\$ 40$ & $\$ 45$ & A & B \\
\hline 7 & $\$ 40$ & $\$ 46$ & A & B \\
\hline 8 & $\$ 40$ & $\$ 47$ & A & B \\
\hline 9 & $\$ 40$ & $\$ 48$ & A & B \\
\hline 10 & $\$ 40$ & $\$ 49$ & A & B \\
\hline 11 & $\$ 40$ & $\$ 50$ & A & B \\
\hline 12 & $\$ 40$ & $\$ 51$ & A & B \\
\hline
\end{tabular}

Table 1: Table used to elicit discount rates from participants.

\begin{tabular}{l|ccc} 
Variable & $\begin{array}{c}\text { Endowment } \\
\text { Treatment }\end{array}$ & $\begin{array}{c}\text { Earnings } \\
\text { Treatment }\end{array}$ & $\begin{array}{c}\text { Returning } \\
\text { Treatment }\end{array}$ \\
\hline \hline A-rate & 4.65 & 4.93 & 8.18 \\
& $(1.17)$ & $(1.55)$ & $(1.74)$ \\
AS1 & 4.96 & 5.00 & 5.09 \\
& $(1.08)$ & $(0.89)$ & $(0.81)$ \\
AS2 & 4.125 & 6.11 & 6.09 \\
& $(0.94)$ & $(0.59)$ & $(0.89)$
\end{tabular}

Table 2: Summary statistics by treatment: mean (standard deviation). 